\title{
Editorial: Only a Three-Legged Stool? A Review of the Concept of Alignment in the Economics of Performance Management
}

\author{
V. G. Sriharan ${ }^{\mathrm{a}}$, Michael S. C. Tse \\ ${ }^{a}$ University of Adelaide, Australia \\ ${ }^{\mathrm{b}}$ Holmes Institute, Australia
}

\begin{abstract}
This editorial revisit the concept of alignment within the agency theoretic view of organisational performance management. Based on an analysis of a real-life case, we examine how far the theoretical reasoning based on the concept of 'three-legged stool' is practically relevant. Findings of our case suggests that while there is seemingly misalignment among the three established structures of performance evaluation, decision right allocation and incentive compensation, the 'misalignment' is 'repaired' with the support of two other governance structures namely, HR and CRM policies. We believe that the design of performance management is not to be confined to the 'three-legged stool' but practically extended to other forms of governance structures.
\end{abstract}

Keywords: Agency Theory; Alignment; Decision Right Allocation; Evaluation; Performance Management; Incentive Compensation

\section{Introduction}

"[The three-legged stool] consists of three aspects of corporate organization: the assignment of decision rights within the company; methods of rewarding individuals; and, the structure of systems to evaluate the performance of both individuals and business units. If one of the legs is shorter, the stool is out of balance. These three elements must be in balance in the organization as well" (Brickley, Smith and Zimmerman, 2015).

The objective of this editorial is to re-examine the agency theoretic concept of alignment among the structures in performance management. 
Based on an analysis of a real-life case, we are convinced that it is now the right time to revisit the frontiers of performance management even within the entrenched literatures such as organisational economics and management control systems.

Agency theory suggests that alignment within a performance management system, a critical requirement for achieving organisational objectives, can be achieved by the use of a consistent set of measures across performance evaluation and compensation structures (Jensen and Meckling, 1992). For instance, studies on performance-based incentive plans (e.g., Baiman 1990; Banker et al., 1996; Callen, Morel \& Fader, 2008; Holmstrom, 1989) suggest that incentive compensation-driven actions positively affect expected outcomes. Coates et al. (1995) and Dikolli (2001) find that alignment between employee incentive compensation system and performance evaluation plan is positively linked to firm value maximisation. Further, studies on total quality initiatives (e.g., Ittner and Larcker, 1995; Wruck and Jensen, 1994) find that successful implementation of systems such as responsiveness and just-in-time (JIT) are positively related to the consistent use of measures for performance evaluation and incentive compensation.

Though the aforementioned agency theory-based studies list performance evaluation and incentive compensation as important organisational structures, they neither argue that these two are the only structures nor identify an exhaustive list of structures within which alignment must occur (see Alchian and Demsetz 1972; Jensen and Meckling, 1992; Callen et al. 2008). To this end, Brickley, Smith and Zimmerman, (2015) is the pioneering work that makes a distinct contribution. By focusing on how authority is distributed within an organisation, they add a new structure titled 'decision rights allocation' and examine how the three structures (i.e., performance evaluation, decision rights and incentive compensation) must be closely aligned to each other in order to achieve overall organisational objectives. Described as the 'three-legged stool', Brickley et al. (2015) suggest that changes in any one the three structures must be aligned with consistent changes in the other two structures such that the whole performance management system stands 'balanced'.

The premise of the 'three-legged stool' is that the set of performance measures used will be consistent across all the three structures. For instance, if a manager is assigned a cost centre responsibility, then the manager must have been notified about a) the decision rights to identify 
cost reduction avenues and execute efficiency improvement procedures, $b$ ) the methods of managerial evaluation of the employee's performance on cost reduction value and efficiency percentage, and c) the type and methods of compensation that rewards cost and efficiency improvements. Note that the measures of cost reduction and efficiency used in this example are consistent across all the three structures.

Consider a new scenario here. The senior manager decides to also evaluate the manager's performance on product quality, an area that the cost centre manager has been ignoring for quite some time. The concept of 'three-legged stool' suggests that unless the senior manager simultaneously offers a) explicit decision authority to the cost centre manager to interact with other supply chain partners in order to develop relevant quality procedures, and b) clarity on how the compensation will also be linked to product quality improvements, the cost centre manager will not only experience difficulty but also less likely to be motivated to embark on product quality performance.

In this editorial, we examine how far the theoretical reasoning based on the concept of 'three-legged stool' is practically relevant. This relevancy test has the potential to extend the theoretical frontiers of performance management. For instance, though the three structures can be apparently aligned with the new product quality measure, the theory does not discuss the possibility of a potential conflict between cost reduction and quality improvement. Moreover, if the cost centre manager holds specific knowledge that is not easily transferable, how can the senior manager convince herself that the cost centre manager is not opportunistically blaming the 'cost demands' of high product quality to justify her genuine poor cost reduction performance? If the senior manager is conscious of such potential opportunism concerns, how do they continue to maintain alignment in the performance management system? Our search for possible answers opened the doors for examining one unique case context. While the findings are limited to the specific context and thus not overly generalisable, the findings still show the need for more context-based studies that can help develop a more theoretically generalisable view of operationalising the alignment concept (a process known as 'analytic generalisation', according to Yin, 1994, pp. 35-40).

Based on the analysis of a single-firm case study, we have identified the existence of simultaneous needs to maintain ex ante measures (customer specifications and delivery time) and to encourage ex post exploration for further innovation as the main reason for the seemingly 
misaligned performance management system design. An aligned design based on customer specifications and delivery time can trigger agency problems such as, 'information-hiding' and 'go-slow'. To control the information-hiding problem, the case study firm removes these measures as the basis for the incentive compensation purpose. On top of it, the inclusion of a different measure (number of new products) for incentive compensation has reduced the team's inclination to delay furtherinnovation on any single project. The presence of an independent governance structure on customer relationship management (CRM) provides a credible deterrence to the teams from focusing exclusively on the incentive compensation measures and ignoring the performance evaluation measures.

Accordingly, we believe that the 'legs' of the 'three-legged stool' are just three among a group of governance structures, where each structure is identified with one or more performance measures. So long as the measures that underlie one structure supports or 'balances' for the misalignment in the choice of measures across the other governance structures, alignment is supposed to exist. In other words, the design of a particular governance structure in a firm's performance management system depends on its ability to contribute to the overall alignment among all other structures in the system.

\section{Background of Case Firm}

The case firm, Potential Refrigeration Incorporated (PRI, a pseudonym) is a medium-sized firm based in Christchurch, New Zealand. PRI designs, manufactures and sells commercial refrigerators across New Zealand, Australia and the Middle East. The manufacturing process involves shearing and punching steel sheets automatically through the flexible manufacturing system (FMS) that processes input data from the computer to determine the set-up, quality and quantity parameters. The punched sheets are folded into the semi-automated press for the folding process. The sheets then pass through the paint line process and are then sent to the assembly section. In the assembly, the sheets are insulated with non-polluting chemicals in a 'foaming' process. The doors and ducts are assembled to the sheets to make 'skeleton' refrigerators. The skeletons are then mounted with compressors. The refrigerators are finally examined in the testing station and forwarded to the packing station. In short, five main processes exist in PRI's manufacturing operation: punching, folding, painting, foaming and assembly. 
Due to increasing competition and the need to customise products with specifications that fell outside the firm's own range of product options, PRI has created an exclusive customer-specified division (in short, CSD) where all of the five processes are carried out within the same division. Note that the rest of the factory produces firm-specified product ranges in five separate process departments for each of the five processes. For ease of comparison, we shall henceforth refer to the rest of the factory as firm-specified division (FSD) ${ }^{1}$. Initially, ten key workers are identified and trained in several processes and assigned to CSD. Over time, ten further employees are hand-picked for this division from both internal and market sources. Although CSD is a small unit within the large main factory, this division is accorded a status worthy of a research and development unit because the new product models created in this division become the feeder for the factory's list of firm-specified models.

Three general managers (human resources, finance and plant) assist the managing director who is also in charge of PRI's marketing function. Several middle-level managers report directly to the three general managers. The managers of design, computing services, maintenance, manufacturing, and technical development report to the plant general manager. The manufacturing function is headed by an operations manager under whom more than 200 workers are employed in various manufacturing processes. First, both divisions are overseen by the same operations manager. However, as FSD is too large for efficient span of control, a process leader is appointed for each process department to collect and provide output information to the operations manager. Further, a group of these processes are managed by a team leader. For instance, the paint line, FMS, steel store and folding process are coordinated by one team leader. The team leader reports directly to the operations manager while a process leader reports to both the team leader and the operations manager. In contrast, the CSD carries out all the process functions in one place, and are coordinated by one process leader, who reports directly to the operations manager.

\footnotetext{
${ }^{1}$ This structure is called the "factory-within-a-factory" within the operations management literature (see Miltenburg, 2008).
} 


\section{Case Study Problem and Analysis}

\subsection{The Case Study Problem}

Within CSD, the operations manager uses 'job plans' to derive benchmark measures in evaluating the overall performance. The job plans list the resources required for a job, the expected unit costs for each resource and the total job costs. The operations manager uses measures from the job plan such as 'customer specifications' and 'delivery time' for each job to evaluate the overall team performance in the division. Since individual performance is difficult to segregate in teamwork, the operations manager reiterated his dependence on the human resources department's governance structure helped in the selection, annual training and appraisal of talented employees who held the intrinsic motivation to carry out innovative tasks that are required in CSD. In terms of decision rights, the job descriptions provide evidence for the decision authority in relation to innovation, interaction and execution of complex tasks in CSD. In relation to the compensation, the evidence obtained from the internal memorandum and interviews suggested the measure on the 'number of new products developed', which had no specific connection with the two measures used under the decision rights and performance evaluation structures.

Theoretically, 'number of new products developed' is a period-based measure and may not correspond with the job-specific measures of 'customer specifications' and 'delivery time'. We have ruled out the possibility that the misalignment is a random occurrence by comparing with the measures used in the FSD, which revealed consistency across all the three structures. Further, we have also verified with the operations manager who discloses his concern about the high degree of knowledge specificity in the CSD and therefore the potential for opportunistic behaviour. The operations manager also clarifies that the FSD and the CSD varied in their contexts, which warrant different treatments. In summary, the evidence from the firm-specified division regarding the measures used for evaluation is consistent with the measures used for providing incentives. Given this trend, there is sufficient reason to believe that the inconsistent measures chosen for the CSD is a deliberate design and that the manager must have had some defensible reasons for such a design choice. Our research problem is therefore to understand the reasons behind this anomaly and how PRI manages the potential illeffects of misalignment in CSD's performance management system. 


\subsection{The Information-Hiding Problem and Solution}

When a new customer order is received, the plant general manager determined the feasibility of making that order together with the operations manager and the CSD process leader. A joint decision by the principal and the agent is efficient when different individuals hold different pieces of specialised knowledge (Jensen and Meckling, 1992; Milne, 2007; Du Plessis, 2007). If the project is accepted, detailed planning is carried out by the process leader and his team and presented for approval prior to execution. The operations manager admits that he applies only an oversight knowledge (because of the high degree of specificity) to approve the detailed plans.

After the completion of a project, customer specifications and delivery time are used to assess the team's performance. Based on the feedback of a prior CRM survey, the operations manager concedes that the potential for workers' opportunistic behaviour in merely carrying out what is initially agreed in the customer specifications and delivery time and not revealing their ideas for any further innovation. This is because of a potential fear among the workers that apart from not gaining any additional value out of such disclosures, they might even lose their rewards if the agreed customer specifications and delivery time are not achieved.

Though PRI managers generally enjoy healthy relations with workers, the human relations (HR) policy statement states that PRI does not want to create control systems that even remotely encourage a worker to indulge in opportunism. Therefore, in response to the need for motivating the workers to reveal further-innovation potential, the plant general manager has decided to remove customer specifications and delivery time as measures for incentive compensation. Consistent with economic theory (Brickley, et al., 2015), removing incentives for concealing innovation ideas does not ensure automatic revelation of the ideas. This is where the PRI's human resource governance structure such as selection, training and appraisal create implicit incentives for not only carrying out and sharing further research ideas.

With the above evidence, we build the initial blocks of the theory as follows. Together with the removal of the two job-specific measures for incentives, the HR governance structure on selection, training and appraisal focuses on retaining employees with commitment and aptitude for challenges, which in turn, helps create the desired implicit incentives for further-innovation. 


\subsection{The 'Go-Slow' Problem and Solution}

Agency theory claims that the downside in creating incentives for a specific innovation activity is that the activity might be pursued even to the extent of detriment to firm's long-term interests unless the firm implements efficient mechanisms for innovation control (Klein and Sorra, 1996). The basic argument is that the creation of incentives for harnessing agents' expertise combines the need for delegation of rights with agents' ability to generate informational rents, which in turn, gives rise to the agents' scope for opportunism indulgence (Jensen and Meckling, 1992; Lazear, 2000; Du Plessis, 2007). In our context, examples of agents' opportunism include deliberate delays or 'go-slow' attitudes in building a new prototype. According to the operations manager:

“...if we motivate the workers (in customer-specified division) to go ahead and innovate further, then they get focused on it consciously or subconsciously. Then they might look at a job and (decide to) take the easy way and work at their own pace (an example of opportunism). We do not have all the time in the world... (Otherwise), we will end up facing a whole lot of totally dissatisfied customers."

Given the need to balance between meeting customer requirements and suggesting further innovation in an environment that offers scope for opportunistic delays, the way to evaluate the customer-specified division workers' performance is a concern that many PRI managers commonly share. The operations manager states:

"I have been discussing (with the plant general manager) on how to evaluate their (CSD workers') performance. It is difficult... You can't really say you have got to do 20 (refrigerators) next month, because sometimes they tell you that even a single order can take two weeks... They (CSD workers) have got the experience and knowledge that I will never have..."

Given the pressures to reduce lead time in innovating for customised products, the operations manager and the plant general manager are forced to adopt the period-based measure, 'number of new products developed', to promote speedy innovation. The indirect expectation is that the measure reduces incentives for opportunistic delays. For the CSD, the effect of all these changes in the choice of measures is the apparent misalignment between a) decision rights and evaluation structures and the b) incentive structure. 
Our study suggests that while PRI managers are aware of the effects of the misalignment, they are reluctant to dispense with the two measures 'customer specifications' and 'delivery time'. It is because these represent job-specific measures that can yield customer satisfaction in case the workers identify that no further-innovation is possible for any particular job without incurring substantial costs. This difficulty is expressed by the operations manager:

"It is difficult... (For customer-specified division), to come up with a formula to measure job performance, and simultaneously motivate innovation and penalise delays, you would need a rocket scientist."

\subsection{The Roles of the HR and CRM Structures}

At the first level, even in a deliberately misaligned design at PRI, we have already seen evidence for the judicious dependence on another governance structure namely, the human resource policy (in selection, training and appraisal) that provides a practical solution to retain intrinsic motivation for further innovation, particularly after the removal of incentives for customer specifications and delivery time. This compensates for the absence of any formal periodic evaluation or reward that is linked to commitment and aptitude for challenges.

At the second level, the tendency to protract innovation is controlled by introducing a new measure, 'number of new products' upon which incentives are based. However, what could still motivate the workers to continue to achieve 'customer specifications' and 'delivery time', when these measures were not linked to rewards? This is where PRI's customer relationship management (CRM) plays a role. Valued customers such as Coca-Cola have partnered with PRI to suggest sources of improvement in potential innovation and customer service. At a minimum, the survey feedback, including criticisms, on any specific job are recorded in a register, which was accessible to all employees in the firm. The fact that it is possible to identify the members who are involved in any specific job provides a deterrence for the CSD worker to ignore the scope for further innovation. Agency theory predicts that when a feedback mechanism is accessible to the principal and other agents, it can trigger a reputation threat for the specific agent on whom the feedback is directed (Fama, 1980; Storey and Barnett, 2000). To protect their reputation, we believe that the workers sought to continually monitor their customer specification and delivery time progress on each job until such time they 
identify avenues for further-innovation, which are agreeable to the customer.

One may inquire why the two subjective indices are not formally included as evaluation or incentive measures, particularly when they play a critical role in linking mismatching set of measures for evaluation and incentives. Evidence suggests that formalising subjective performance measures is costly due to lack of transparency and assessment difficulty. The operations manager concludes:

"The whole area of performance measurement and monitoring ... we are developing it, but we are trying to target objective standards that can be easily assessed rather than mere subjective (measures)... (However,) I have come to realise that other governance mechanisms such as the HR and CRM suits well here (in the CSD). So where needed, we may use them, but only to the extent needed."

\section{Scope for Future Research}

This editorial aims to encourage further research on performance management in specific reference to agency theory. We believe that there is a huge potential for further research in this area, given that the theory is still to recognise the roles of multiple governance structures that are in concurrent operation in a firm. Our case study context is in custom manufacturing but we believe that there could be many other contexts that might warrant the analysis of a more generic governance structurebased model of performance management. Findings of our case suggests that while there is seemingly misalignment among the three established structures of performance evaluation, decision right allocation and incentive compensation, the 'misalignment' is 'repaired' with the support of two other governance structures namely, HR and CRM policies. In the same vein, we believe that there could be other governance structures such as continuous improvement, and JIT, which might lend support to restore the alignment. It is high time that management accounting researchers embark on the journey of developing a holistic modelling of performance management, perhaps one that is based why and how multiple governance structures exist to provide support to each other in ensuring the firm to achieve its overall objectives! 


\section{References}

Alchian, A. and H. Demsetz (1972) "Production, Information Costs and Economic Organization," American Economic Review, Vol. 62 No. 5, pp. 777-795

Baiman, S., (1990), "Agency Research in Managerial Accounting: A Second Look", Accounting, Organizations and Society, Vol. 15 No. 4, pp. 341-371.

Banker, R. D., Lee, S. Y., Potter, G. and Srinivasan, D., (1996), "Contextual Analysis of Performance Impacts of Outcome-Based Incentive Compensation", Academy of Management Journal, Vol. 39 No. 4, pp. 920-948.

Brickley, J. A., Smith, C. W. and Zimmerman, J. L., (2015), Managerial Economics and Organisational Architecture, Irwin McGraw Hill, Boston.

Callen, J. L., Morel, M. and Fader, C., (2008), “An Empirical Analysis of the Incentive-Action-Performance Chain of the Principal-Agent Model", Journal of Management Accounting Research, Vol. 20 No. S1, pp. 79105.

Christie, A. A., Joye, M. P. and Watts, R. L., (2003), "Decentralization of the Firm: Theory and Evidence", Journal of Corporate Finance, Vol. 9 No. 1, pp. 3-36.

Coates, J., Davis, T. and Stacey, R., (1995), "Performance Measurement Systems, Incentive Reward Schemes and Short-Termism in Multinational Companies: A Note", Management Accounting Research, Vol. 6 No. 2, pp. 125-135.

Dikolli, S. S., (2001), “Agent Employment Horizons and Contracting Demand for Forward-Looking Performance Measures", Journal of Accounting Research, Vol. 39 No. 3, pp. 481-494.

Du Plessis, M., (2007), "The Role of Knowledge Management in Innovation”, Journal of Knowledge Management, Vol. 11 No. 4, pp. 4164.

Fama, E. F., (1980), "Agency Problems and Theory of the Firm”, Journal of Political Economy, Vol. 88 No. 1, pp. 288-306.

Holmstrom, B., (1989), "Agency Costs and Innovation", Journal of Economic Behavior and Organization, Vol. 12 No. 3, pp. 305-327. 
Ittner, C. D. and Larcker, D. F., (1995), "Total Quality Management and the Choice of Information and Reward Systems", Journal of Accounting Research, Vol. 33 No. S1, pp. 1-34.

Ittner, C. D. and Larcker, D. F., (2002), "Determinants of Performance Measure Choices in Worker Incentive Plans", Journal of Labour Economics, Vol. 20 No. S2, pp. 58-90.

Ittner, C. D., Larcker, D. F. and Rajan, M. V., (1997), "The Choice of Performance Measures in Annual Bonus Contracts", The Accounting Review, Vol. 72 No. 2, pp. 231-255.

Jensen, M. C. and Meckling, W. H., (1992), "Specific and General Knowledge and Organisational Structure", In L. Werin and H. Wijkande (ed.), Contract Economics, Blackwell, Oxford.

Klein, K. J. and Sorra, J. S., (1996), "The Challenge of Innovation Implementation", Academy of Management Review, Vol. 21 No. 4, pp. 1055-1080.

Lazear, E. P., (2000), "Performance Pay and Productivity", American Economic Review, Vol. 90 No. 5, pp. 1346-1361.

Milne, P., (2007), "Motivation, Incentives and Organisational Culture", Journal of Knowledge Management, Vol. 11 No. 6, pp. 28-38.

Miltenburg, J., (2008), "Setting Manufacturing Strategy for a Factorywithin-a-Factory", International Journal of Production Economics, Vol. 113 No. 1, pp. 307-323.

Storey, J. and Barnett, E., (2000), "Knowledge Management Initiatives: Learning from Failures", Journal of Knowledge Management, Vol. 2 No. 2, pp. 145-156.

Wruck, K. and Jensen, M., (1994), "Science, Specific Knowledge and Total Quality Management", Journal of Accounting and Economics, Vol. 18 No. 3, pp. 247-287.

Yin, R. K., (1994), Case Study Research: Design and Methods, Sage Publications, Thousand Oaks. 